\title{
A LINGUÍSTICA COGNITIVA NA SALA DE AULA:
} ENCAMINHAMENTOS POSSÍVEIS

\author{
Dedilene Alves de Jesus*
}

\begin{abstract}
RESUMO: O artigo objetiva apresentar os pressupostos da Linguística Cognitiva como ferramentas viáveis para a análise de práticas pedagógicas em sala de aula. Partindo das iniciativas de Alves (2005) e Gerhardt (2006), defendemos que a análise através de conceitos cognitivistas como frame, cena de atenção conjunta, perspectivação conceptual, MCI (modelo cognitivo idealizado), espaços mentais e categorização seja uma contribuição para a melhoria das práticas docentes e da compreensão dos processos de ensino e de aprendizagem nas diferentes disciplinas perpassadas pelas linguagens. Nesse viés, apresentamos também algumas perspectivas para os estudos da Linguística Cognitiva como base para análise de práticas pedagógicas e também para a produção de protocolos e materiais didáticos voltados para o desenvolvimento das habilidades de leitura, escrita, fala e escuta.
\end{abstract}

PALAVRAS-CHAVE: Linguística Cognitiva. Ensino. Prática pedagógica.

\section{Introdução}

Há mais de 30 anos surgiu o quadro teórico da Linguística Cognitiva, a partir de autores como Lakoff e Johnson (1986), Croft e Cruse (2004), como uma abordagem linguística derivada da corrente gerativista, em um movimento de ruptura com a perspectiva formalista. A Linguística Cognitiva, doravante LC, nesse sentido, estabeleceu os seguintes pressupostos:

* Doutora em Letras pela Universidade Federal do Rio de Janeiro (UFRJ). Professora da Universidade do Estado de Minas Gerais (Uemg). 
- A linguagem não é um módulo separado de outras faculdades cognitivas.

- A estrutura gramatical de uma língua reflete diferentes processos de conceptualização.

- O conhecimento linguístico emerge e se estrutura a partir do uso da linguagem, ou seja, do uso efetivo da língua em eventos comunicativos reais.

De alguma forma, ao estabelecer esses pressupostos, a LC contraria a abordagem estruturalista que estabelece a linguagem como um sistema autônomo, que se basta a si mesmo, sem vinculação com outros aspectos que não sejam de natureza linguística; também contraria o pressuposto gerativista da visão modular da mente, em que o módulo cognitivo da linguagem é visto também como independente de outros módulos cognitivos (do raciocínio lógico-matemático, da percepção, por exemplo).

A “novidade” trazida pela LC refere-se à abordagem da cognição como um sistema complexo e dinâmico, que funciona a partir de compartilhamentos entre linguagem e capacidades cognitivas diversas, partindo do experiencialismo do indivíduo. A essa noção de experiencialismo se atrela à perspectiva das vivências práticas, corpóreas, uma vez que é através do corpo que percebemos o mundo. Daí a noção do termo "corporificação da mente", muito abordado pela LC. E o que vem a ser isso?

Na perspectiva cognitivista, a linguagem é permeada por conceptualizações que, por sua vez, se fundamentam em experiências corporificadas. Ou seja, os conceitos que internalizamos acerca de uma palavra advêm das experiências que tivemos com a representação dela (objeto) de forma pessoal ou ancestral (conhecimento adquirido e estabelecido em uma cultura). Exemplificando: a noção de construções como "em cima”, "embaixo", "mais" e "menos" é estabelecida a partir da noção espacial do ser humano que habita em um mundo que sofre os efeitos da gravidade; se vivêssemos na Lua, onde não há gravidade, essas noções poderiam ser outras. Há nessa questão a prevalência do relativismo linguístico, que nos faz atribuir sentido a uma palavra segundo o contexto em que se encontra e não de forma aleatória. 
Apesar de possuir um aporte voltado para as questões práticas da linguagem, a LC ainda se estabelece em um patamar alijado da sala de aula, sem ser considerada pela Linguística Aplicada como abordagem interessante para as questões voltadas para o âmbito das práticas pedagógicas.

O que observamos é que os pressupostos da LC estabelecem um nicho muitas vezes direcionado para os estudos da Psicologia Cognitiva, que certamente cumpre o seu papel enquanto ciência voltada para questões psicológicas, mas não consegue englobar, por exemplo, aspectos sociocognitivos e metacognitivos dos processos de aquisição e desenvolvimento da leitura e da escrita.

Com isso, não queremos estabelecer um "pedestal” para a LC, mas propor uma abordagem de conceitos dessa corrente teórica nos estudos voltados para as práticas pedagógicas/didáticas, na percepção de que existem ganhos a serem considerados nessa perspectiva. Obviamente, há iniciativas já realizadas nessa frente, que serão explanadas a seguir.

\section{Por que a Linguística Cognitiva?}

A LC passou a ser divulgada como um paradigma científico a partir da publicação da revista Cognitive Linguistics (Alemanha/1989), que reunia estudos sobre as diversas línguas, apresentando análises específicas. O termo "linguística cognitiva" foi adotado inicialmente por um grupo de estudiosos (George Lakoff, Ronald Langacker, Leonard Talmy, Gilles Fauconnier, entre outros) que realizavam pesquisa em Semântica Gerativa e, diante da insatisfação com o papel da Semântica e da Pragmática nessa abordagem, decidiram abandonar esse modelo e se dedicarem a uma nova abordagem.

Nesse primeiro momento, o que coube a eles foi estabelecer os conceitos que serviriam como base para a LC. Assim, a primeira defesa está na seguinte premissa: a relação entre palavra e mundo é mediada pela cognição. Dessa forma, o significado é visto como uma construção cognitiva através da qual o mundo é apreendido ou experienciado. Então, não é a palavra que contém um significado, mas o sujeito é quem atribui um significado a ele, segundo seu experiencialismo, que é afetado pela cultura. 
Algumas obras se tornaram basilares para o conhecimento da LC, dada a sua importância no sentido de apresentar os conceitos dessa corrente e as rupturas com o gerativismo e o estruturalismo. Citamos duas: Women, fire, and dangerous things (LAKOFF, 1987), que, a partir da interface entre estudos antropológicos e linguísticos, mostra como as categorias são flexíveis, uma vez que o processo de categorização varia culturalmente; Metaphors we live by/Metáforas da vida cotidiana (LAKOFF E JOHNSON, 1980), que apresenta a metáfora conceptual, termo para se referir a um processo cognitivo de relação entre domínios, mostrando que muitas frases usuais nossas são frutos de processos metafóricos complexos.

No Brasil, segundo Chiavegatto (2009), a LC começa a ser divulgada a partir de estudos de Margarida Salomão, no início dos anos 2000; a principal contribuição dos estudos brasileiros tem sido no campo da Semântica, mas há também estudos de interface léxico-gramática, semântica-sintaxe e semântica-discurso. O diálogo com outras linhas de pesquisa, de base funcionalista e das ciências cognitivas e sociais, tem ocorrido como forma de exploração das relações entre linguagem, cultura e cognição.

A pesquisa educacional focada nas práticas pedagógicas tem sido, nos últimos anos, realizada a partir de suportes teóricos cada vez mais atualizados. Não se concebe, por exemplo, pesquisar um manual didático com base em pressupostos didáticos do início da década de 90, pois após esse período muito já se avançou e hoje existe uma variedade de conceitos a serem considerados quando falamos sobre esse tipo de análise (se o manual foi de Língua Portuguesa, há de se considerar os multiletramentos, a perspectiva sociointeracionista do material, a abordagem baseada na visão enunciativa-discursiva da linguagem, etc).

Por causa desse avanço na pesquisa e do surgimento de novas abordagens para determinada área pedagógica, justificamos a utilização dos pressupostos da Linguística Cognitiva na análise das práticas pedagógicas de sala de aula. Esse movimento de transposição de uma corrente teórica até então considerada específica para estudos de fenômenos linguísticos para a área pedagógica (do ensino) não é novo: Bortoni-Ricardo, professora titular de Linguística da Universidade de Brasília (UnB) e sociolinguista reconhecida, em 
2004 lançou o livro "Educação em língua materna: a sociolinguística na sala de aula". Um dos objetivos do livro foi tratar da questão da variação linguística, principalmente as variantes desprestigiadas, mostrando como o professor poderia lidar com essa questão e combater o preconceito linguístico. O livro tornou-se referência nos estudos sociolinguísticos voltados para o ensino, abrindo caminho para vários trabalhos focados na sala de aula. Até então, fazer essa transposição era considerado quase uma "heresia".

Nesse pensamento, acreditamos ser possível, a partir de um recorte contextual, fazer uma abordagem de questões da sala de aula pela Linguística Cognitiva, uma vez que tal corrente teórica já está consolidada nos estudos brasileiros e tem se mostrado profícua na interface com várias abordagens, tomando um caráter interdisciplinar (há estudos da LC com a Psicolinguística, a Neurolinguística, estudos computacionais e de inteligência artificial, por exemplo).

\section{Pressupostos teóricos da Linguística Cognitiva}

Nesta seção, apresentaremos os conceitos considerados pilares nos estudos de LC. Certamente, há outros conceitos não menos importantes que não estão elencados aqui por entendermos que são subjacentes a esses pilares.

A noção básica para aquisição da linguagem e aprendizagem foca-se na cena de atenção conjunta; segundo Tomasello (2003), a partir dos 9-12 meses, a criança aprende comportamentos triádicos, isto é, interage com o adulto e o objeto da cena conjunta. Essa relação é formadora do frame de atenção conjunta, uma das três manifestações importantes para a aquisição da linguagem - as outras duas são a compreensão de intenções comunicativas e a aprendizagem cultural na imitação por inversão de papéis. Compreendemos que a atenção conjunta exerce uma importante função na vida de qualquer indivíduo, mesmo após o período de sua maturação, pois é a partir dessa relação que o sujeito consolida sua referência espacial e, consequentemente, sua organização discursiva é influenciada por essa relação ao longo de sua vida. Entendemos que a cena de atenção conjunta seja essencial 
para a construção de conhecimentos por parte dos alunos, através do tripé professor/conhecimento/aluno.

Ao falarmos sobre atenção conjunta, não há como não nos referirmos a frames. $O$ frame designa um sistema de conceitos relacionados de tal forma que, para se compreender qualquer um deles, é necessário entender toda a estrutura na qual ele se insere (FILLMORE, 1982); é também denominado cena ou enquadre, auxiliando na compreensão adequada de um conceito. O significado das palavras é subordinado a frames, uma vez que somente a interpretação da cena pode dar suporte para a compreensão de um termo. Ex.: os verbos comprar, vender, pagar, gastar, custar e cobrar são interpretados porque acessamos o frame de "evento comercial" (em que temos os elementos mercadoria, comprador, valor e vendedor). Em qualquer aula, são ativados frames para as questões de ensino-aprendizagem dos alunos. A compreensão desses frames por parte dos alunos é um dos nossos objetos de pesquisa.

A respeito da perspectivação conceptual, termo fundamental nos estudos cognitivistas, Silva e Batoréo (2010, p. 233) referem-se a ela como “(...) modo ou modos de conceptualizar determinada situação"; estudos da linha norte-americana também a denominam construal (LANGACKER, 2008). Seria a maneira como o indivíduo enxerga uma determinada cena (frame). Na perspectiva da sala de aula, o professor lida com várias perspectivações conceptuais ao mesmo tempo, uma vez que cada aluno traz em si vivências que o fazem conceptualizar o mundo/a linguagem de uma forma. O papel do professor é mediar a construção do conhecimento a partir de estratégias de categorização adequadas.

A categorização, nos termos de Ferrari (2011, p. 31), "é o processo através do qual agrupamos entidades semelhantes (objetos, pessoas, lugares etc) em classes específicas”. A habilidade de categorizar é intrínseca ao ser humano e as estratégias para esse processo 
estão relacionadas à nossa capacidade de memória. A LC reconhece a função categorizadora da linguagem, manifestada na base de protótipos ${ }^{1}$ (exemplares típicos mais representativos). Além da prototipicidade, o processo de categorização envolve outras características estruturais como polissemia, metáfora, metonímia e imagens mentais.

Os Modelos Cognitivos Idealizados (MCI), segundo Silva (2001), são bases relativamente estáveis de conhecimento, bem como os esquemas imagéticos e as molduras comunicativas. MCI seria o conhecimento sobre o domínio ou domínios da experiência que colabora na significação de uma categoria linguística; ele é interindividualmente partilhado pelos membros de um grupo social, tem limite indeterminado e está envolvido em qualquer ato de categorização, sendo imprescindível para formação do significado e pensamento de uma língua. Alguns MCIs são exclusivamente culturais, podendo sua atuação sobre um determinado objeto ou situação divergir de cultura para cultura. Exemplificando: o conceito da palavra "mãe" passa por um modelo cognitivo idealizado de acordo com a cultura - em sua maioria, traz consigo a ideia de proteção, de sustento e de cuidado. À medida que uma palavra vai expandindo seu sentido, esse MCI sofre alteração; é o que ocorre com a palavra "vilão": etimologicamente referia-se ao morador de uma vila, mas na atualidade é associado a alguém perverso, maldoso (muito provavelmente pela analogia do radical vilcom a palavra "vil", que significa indigno, infame).

Os espaços mentais são compreendidos como construtos teóricos temporários para informação relevante sobre um domínio particular (COULSON E FAUCONNIER, 1999), ou seja, são projeções realizadas à medida que o discurso se desenvolve. No entendimento de que todo discurso se realiza em um contexto, temos um domínio-base e projetamos no

\footnotetext{
${ }^{1}$ A respeito da teoria dos protótipos, Silva (1997, p. 3) afirma o seguinte: "Esta concepção da categorização, conhecida como teoria do protótipo, tem a sua origem na investigação psicolinguística de Eleanor Rosch e seus discípulos sobre a categorização das cores, das aves, dos frutos e de outras classes de entidades, e foi, depois, desenvolvida em duas direcções: no âmbito da Psicologia, com vista à elaboração de modelos formais da memória conceptual humana, de interesse também para a Inteligência Artificial (cf. Smith \& Medin 1981, Medin \& Smith 1984, Neisser ed. 1987); e no campo da Linguística e, em particular, no da Semântica Lexical, sob a designação de Semântica do Protótipo (cf., entre outros, Coleman \& Kay 1981; Geeraerts 1985, 1988b,c,d, 1989, 1997; Wierzbicka 1985; Craig ed. 1986; Lakoff 1987; Kleiber 1990; Tsohatzidis ed. 1990; Taylor 1995)”.
} 
discurso um domínio específico, como ocorre na frase "Na Europa, está fazendo calor.": há o espaço-base do falante (que está ligado ao seu local de fala) e a construção " $\mathrm{Na}$ Europa" é um construtor de espaço mental, pois projeta para uma situação fora do local de fala (continente europeu). Em sala de aula, existem muitas projeções realizadas tanto por professores quanto pelos alunos, gerando às vezes uma interpretação equivocada de um discurso expositivo de uma das partes. Como os turnos de fala dentro da sala às vezes não são bem marcados, a ausência de um eixo de focalização na exposição de conteúdos pode gerar problemas na aprendizagem.

Outras premissas da LC precisam ser elencadas neste momento, para a compreensão dos seus objetos de estudo. Tais tópicos foram citados por Chiavegatto (2009, p. 8283), baseados nos estudos de Augusto Silva, precursor da LC em Portugal:

$1^{\circ}$ - a primazia dos estudos semânticos em decorrência da própria perspectiva adotada, ou seja, se a função da linguagem é a categorização, então a significação será o fenômeno linguístico primário; $2^{\circ}$ - que se a linguagem serve para categorizar o mundo, então o significado linguístico não pode ser dissociado do conhecimento do mundo e, por isso mesmo, não se pode postular a existência de um nível estrutural ou sistêmico de significação distinto do nível de conhecimento em que está associado às formas linguísticas; e $3^{\circ}$ - que se a função categorizadora da linguagem impõe estruturas e formas ao conhecimento, então este não está objetivamente refletido nela: ao invés de espelhá-lo, a linguagem é um meio de interpretá-lo, construí-lo e organizá-lo, refletindo as necessidades, os interesses e as experiências dos indivíduos e de suas culturas.

Esses são alguns dos pressupostos da LC que embasam as análises sobre diversos aspectos linguísticos, sempre levando em consideração a perspectiva vygotskiana do indivíduo como ser histórico-social, com vivências relacionadas às influências culturais do seu meio. O nosso enfoque, neste artigo, é apresentar as abordagens possíveis para esses conceitos na sala de aula, considerando-se o trabalho com a linguagem a ferramenta mais utilizada pelo professor; independentemente do conteúdo lecionado, a aula gira em torno da interação pela linguagem (ou esse deveria ser o suporte fundamental de uma aula). 


\section{Iniciativas de estudos da Linguística Cognitiva em situações de sala de aula}

Estudos sobre os conceitos da LC aplicados ao ensino são muito comuns quando nos referimos à aprendizagem de uma segunda língua; os trabalhos de Barbosa (2015) e Portal (2014) são somente alguns dos inúmeros nessa abordagem, sendo o último na linha da Linguística Aplicada. Encontrar estudos específicos sobre a questão da cognição atrelada à interação em sala de aula torna-se um desafio maior.

Quando nos remetemos ao início dos anos 2000, encontramos dois estudos que corroboram para as questões de sala de aula: o de Alves (2005) e o de Gerhardt (2006). O primeiro é uma pesquisa de doutorado que analisa, a partir de conceitos básicos da LC, as estratégias produtivas e não produtivas de interação em sala de aula entre aluno e professor, com vistas à construção de conhecimentos pelo aluno; o enfoque da autora é na construção conceptual gerada em sala de aula a partir da interação entre professor e aluno a partir das noções de MCI (modelo cognitivo idealizado), mesclagem conceptual (blending) e espaços mentais (mental spaces). A análise foi realizada em aulas de Português e Ciências nos anos finais do Ensino Fundamental; Alves (2005, p. 250) chega à seguinte conclusão:

O que observamos de fato, mediante a observação das aulas, é que a função primeira da instituição escolar parece ser a transmissão dos conhecimentos, independente de haver ou não interação dialogada, compartilhamento de sentidos, coconstrução de tópicos. Em contraposição a essa postura, e defendendo a construção de conceitos dentro de uma perspectiva sociocognitiva, entendemos que a interação entre os sujeitos ocupa um lugar de destaque no desenvolvimento cognitivo do aprendiz.

O estudo de Gerhardt (2006) abrange uma situação mais específica, relacionada à interpretação de texto feita pelos alunos, com a seguinte problemática: até que ponto a resposta "errada" do aluno em uma interpretação não está ligada à falta de estratégias que desenvolvam uma percepção mais apurada? A partir da noção de domínios cognitivos, MCI, esquemas imagéticos e molduras comunicativas, a autora respalda o seguinte em suas considerações:

(...) é possível supor que as noções de "certo" e "errado" podem estar intimamente vinculadas a concepções escolares muito menos 
comprometidas com a aquisição e manipulação de informação do que com a internalização de certos saberes sociais. Em outras palavras, se o aluno sabe o que a escola espera que ele saiba e não se ele consegue relacionar e expressar conceitos. E, quanto a isso, podemos também conjeturar em que medida esses saberes são justamente os relacionados a uma elite sociocultural, e autorizados pela escola. (GERHARDT, 2006, p. 120)

Outro estudo, mais atualizado, sobre a abordagem pedagógica para o ensino de gramática em língua materna, especificamente nos anos finais do Ensino Fundamental, é realizado por Roxo (2013). De início, a autora problematiza o distanciamento entre o que se ensina na escola sobre aspectos sintáticos e o que deveria ser ensinado, baseada em duas afirmações: a) a Gramática é dinâmica; b) a Gramática é baseada no uso e na experiência. O conteúdo focalizado refere-se às construções condicionais, em uma proposta didática envolta pela Gramática das Construções, abordagem cognitivista difundida pela linguista norte-americana Adele Goldberg.

Diante desses estudos apresentados, cabe-nos ressaltar que nenhum deles aborda questões pedagógicas, ligadas a materiais didáticos, envolvendo as séries iniciais do Ensino Fundamental, o que nos leva à tendência de apresentarmos possíveis encaminhamentos de propostas viáveis para tal segmento. Antes, porém, apresentaremos os pressupostos que embasam a Linguística Cognitiva enquanto corrente teórica voltada para os estudos da linguagem.

\section{Linguística Cognitiva e sala de aula: alinhamentos possíveis}

Quando nos referimos ao alinhamento Linguística Cognitiva-ensino, a impressão que se tem é do cometimento de uma "heresia" epistemológica, uma vez que estudos voltados para processos complexos da linguagem, dos bastidores da cognição, são geralmente alinhados somente a áreas de cunho mais teórico e "mais científico". Para o campo do ensino, no senso comum, sobram aquelas abordagens teóricas pedagógicas, na interface com a Psicologia, em que se fala sobre distúrbios de aprendizagem e níveis de aprendizagem, dentre outros temas. 
Insistimos no alinhamento LC-ensino por compreendermos que não deva existir essa discrepância entre o que seja considerado mais teórico e o que seja mais prático, entre o que é "mais" ou "menos" científico. Os pressupostos da LC foram elaborados para estudos que abordem o linguístico e reafirmamos que toda aula é perpassada pelo linguístico; dessa forma, existe um campo de pesquisa para a LC ainda a ser explorado. A questão, agora, é outra: Como realizar esses estudos? Que tipo de aula pode ser analisada seguindo os conceitos da LC? Que bases de análise utilizar, por exemplo, na apresentação de uma situação de aula em que um aluno não compreende os conceitos apresentados pelo professor? Que objetos de pesquisa podem ser considerados para uma análise eficaz pela LC? Esse tipo de análise é realmente produtivo?

Inicialmente, para corroborarmos a necessidade de estudos cognitivistas nas situações de sala de aula, buscamos fundamentação nos documentos oficiais da educação em âmbito nacional, quais sejam PCN (Parâmetros Curriculares Nacionais) e BNCC (Base Nacional Comum Curricular). Os PCN datam de 1997 e são considerados documentos básicos para, como diz o seu nome, parametrizar a perspectiva de ensino brasileira; a BNCC é um documento mais novo, tendo seu texto final sido aprovado em dezembro de 2017, na expectativa de "uniformizar" o currículo nas escolas brasileiras. Como visto, são dois documentos com caráter norteador.

Os PCN tratam da questão do ensino de Língua Portuguesa nos anos iniciais do Ensino Fundamental na abordagem do texto como objeto de ensino e enfatizam a diversidade de gêneros discursivos como parâmetro adequado para o trabalho docente. Apresenta também objetivos gerais para o ensino de LP. Desses objetivos, destacamos dois:

“• utilizar a linguagem como instrumento de aprendizagem, sabendo como proceder para ter acesso, compreender e fazer uso de informações contidas nos textos: identificar aspectos relevantes; organizar notas; elaborar roteiros; compor textos coerentes a partir de trechos oriundos de diferentes fontes; fazer resumos, índices, esquemas, etc.;

- valer-se da linguagem para melhorar a qualidade de suas relações pessoais, sendo capazes de expressar seus sentimentos, experiências, ideias e opiniões, bem como de acolher, interpretar e considerar 
os dos outros, contrapondo-os quando necessário" (PCN Língua Portuguesa, 1997, p. 33)

O primeiro objetivo aponta aspectos ligados aos níveis de letramento esperados para o aluno das séries iniciais, tendo em vista que o letramento refere-se a práticas sociais de leitura e escrita, níveis esses a serem desenvolvidos nas diversas atividades escolares e em outras situações sociais; o segundo aponta também para o letramento, mas dentro de situações que extrapolem a sala de aula ${ }^{2}$. De qualquer forma, nos dois objetivos fica clara a noção de uma linguagem baseada no uso, um pressuposto que se alinha à visão da Linguística Cognitiva.

Quanto à BNCC, observamos em seu texto inicial sobre a área de Linguagens ${ }^{3} \mathrm{o}$ seguinte:

As linguagens, antes articuladas, passam a ter status próprios de objetos de conhecimento escolar. O importante, assim, é que os estudantes se apropriem das especificidades de cada linguagem, sem perder a visão do todo no qual elas estão inseridas. Mais do que isso, é relevante que compreendam que as linguagens são dinâmicas, e que todos participam desse processo de constante transformação. (BNCC, 2017, p. 61)

É possível percebermos que o uso do plural (linguagens) acarreta a consideração de que lidamos com multiletramentos e, nesse viés, não se trata de uma linguagem pautada somente no grafocentrismo, mas no espraiamento do termo para as diversas manifestações da linguagem, conforme o próprio documento aborda, devido ao advento de tecnologias digitais de informação e comunicação (TDIC) e também à expressividade característica da dança, do esporte e das manifestações culturais como um todo. Dessa forma, o documento ratifica:

Compreender as linguagens como construção humana, histórica, social e cultural, de natureza dinâmica, reconhecendo-as e valorizando-

\footnotetext{
${ }^{2}$ Não estamos afirmando aqui que tais situações não possam ocorrer na escola, mas o que se percebe é que se caracterizam mais em um âmbito social mais amplo.

${ }^{3}$ Ressaltamos que a área de Linguagens da BNCC engloba as seguintes disciplinas: Língua Portuguesa, Arte, Educação Física e Língua Inglesa. 
as como formas de significação da realidade e expressão de subjetividades e identidades sociais e culturais. (BNCC, 2017, p. 63)

Assim, entendemos que a questão sociocultural perpassa os aspectos linguísticos, mais uma vez se encontrando com o que a LC afirma sobre a consideração do experiencialismo como base para a fundamentação da linguagem.

Voltando aos questionamentos apresentados no segundo parágrafo desta seção, cremos que, após essas articulações, temos condições de propor encaminhamentos. Para isso, eles serão recolocados aqui na configuração de perguntas que merecem alguma resposta:

\section{a) Como realizar estudos de LC em sala de aula?}

A essa pergunta, é tentador pensar em inúmeros aparatos sendo alocados em uma sala de aula no intuito de registrar todas as situações da aula, problematizando e apontando "soluções" para as questões linguísticas decorrentes de um mal entendido na explicação do professor ou uma resposta considerada "errada", mesmo quando se percebe a lógica do falante por trás dessa resposta. Esse idealismo não corresponde ao que um estudioso em LC geralmente realiza, muito embora existam estudos voltados para programas computacionais que tabulam e balizam uma determinada situação comunicativa (a Semântica de Frames atua muito bem nesse aspecto).

O estudo da LC em sala de aula, a nosso ver, ocorreria de forma mais simples: um caderno de campo para anotações, uma possível gravação daquele momento da aula e subsequente transcrição, entrevistas prévias com os professores das turmas, questionários para os alunos, protocolos de interpretação de textos e, principalmente, noção clara por parte do investigador dos conceitos da Linguística Cognitiva a serem abordados nos processos cognitivos decorrentes em sala. Utilizamos esses recursos para análise de dados que nos levem a discussões efetivas de situações reais de sala e ao levantamento daquelas que podem ser melhoradas. Metodologias bem usuais em qualquer nível de pesquisa linguística com foco pedagógico-didático. A essas metodologias damos nomes variados, dependendo do 
enfoque requerido, mas optaremos aqui pelo termo "pesquisa-ação", especificamente "pesquisa-ação educacional", entendendo que para toda pesquisa pedagógica há uma análise e algumas propostas de intervenção.

Tripp (2005, p. 445) define a pesquisa-ação como "uma estratégia para o desenvolvimento de professores e pesquisadores de modo que eles possam utilizar suas pesquisas para aprimorar seu ensino e, em decorrência, o aprendizado de seus alunos (...)". Esse tipo de pesquisa faz parte do campo da investigação-ação. Tripp propõe o seguinte esquema para as fases do ciclo básico desse tipo de investigação:



Figura 1 - Diagrama da investigação-ação

Fonte: TRIPP, 2005, p. 446

Observamos que é um sistema cíclico, em que uma das leituras pode ser a seguinte: a partir da observação de uma dada situação, há um planejamento para melhorar a prática, a implantação dessa melhoria, o monitoramento e descrição da ação e a consequente avaliação dos resultados dessa prática.

De forma prática, Tripp (2005) apresenta uma tabela que explicita a diferença entre a pesquisa-ação, a prática rotineira e a pesquisa científica. Cremos que o autor faz uso desse 
recurso como forma de demonstrar o papel da pesquisa-ação em estudos investigativos na área educacional.

\begin{tabular}{|c|l|l|l|}
\hline \multicolumn{4}{|l|}{ Tabela 1: Onze caracteristicas da pesquisa-ação } \\
\hline Linha & Prática rotineira & Pesquisa -ação & Pesquisa científica \\
\hline $\mathbf{1}$ & habitual & inovadora & original / financiada \\
\hline $\mathbf{2}$ & repetida & contínua & ocasional \\
\hline $\mathbf{3}$ & Reativa contingência & pro-ativa estrategicamente & metodologicamente conduzida \\
\hline $\mathbf{4}$ & individual & participativa & colaborativa / colegiada \\
\hline $\mathbf{5}$ & naturalista & intervencionista & experimental \\
\hline $\mathbf{6}$ & nāo questionada & problematizada & contratual (negociada) \\
\hline $\mathbf{7}$ & com base na experiència & deliberada & discutida \\
\hline $\mathbf{8}$ & năo-articulada & documentada & revisada pelos pares \\
\hline $\mathbf{9}$ & pragmática & compreendida & explicada / teorizada \\
\hline $\mathbf{1 0}$ & específica do contexto & & generalizada \\
\hline $\mathbf{1 1}$ & privada & disseminada & publicada \\
\hline
\end{tabular}

Tabela 1 - Características da pesquisa-ação

Fonte: TRIPP, 2005, p. 447

Julgamos que seja suficiente a apresentação dos esquemas de Tripp para justificar o uso da pesquisa-ação como ferramenta nas análises da LC no ensino. Passaremos, então, à próxima pergunta.

\section{b) Que tipo de aula pode ser analisada seguindo os conceitos da LC?}

Quanto à tipologia das aulas analisadas, não existe um parâmetro. Podem ser analisadas as aulas em que o discurso linguístico esteja presente, seja na forma oral ou escrita; quando estabelecemos esse parâmetro, observamos que toda aula pode ser analisada, uma vez que a linguagem é seu componente essencial.

Neste artigo, especificamos a abordagem nas aulas que ocorrem no $1^{\circ}$ segmento do Ensino Fundamental, a saber, do $1^{\circ}$ ao $5^{\circ}$ ano de escolaridade, em todas as disciplinas. Obviamente, por causa da afinidade, as aulas de Língua Portuguesa nesses anos de escolaridade serão mais proveitosas para as análises, pois, além do discurso linguístico, serão observados os conceitos e conteúdos inerentes às linguagens. 
Quando fazemos esse recorte para análise, nos deparamos com a questão do processo de alfabetização, que abarca os dois primeiros anos de escolaridade. Como as abordagens teóricas para a aquisição da escrita já possuem um viés cognitivista (Emília Ferreiro era da área de Psicologia Cognitiva), não vemos maiores dificuldades para o trabalho de percepção dos processos aqui mencionados nesse período de desenvolvimento. Tomamos como base a noção de que a alfabetização é um processo que necessita de técnica/método para ser desenvolvido (SOARES, 2017).

c) Que bases de análise utilizar, por exemplo, na apresentação de uma situação de aula em que um aluno não compreende os conceitos apresentados pelo professor?

Cremos que, descartadas as situações de distúrbio do aluno, as bases serão aquelas relacionadas aos pressupostos da Linguística Cognitiva: a verificação das projeções que esse aluno realiza enquanto o professor apresenta o conceito; o Modelo Cognitivo Idealizado desse aluno a respeito do assunto tratado; o tipo de mediação realizada pelo professor, baseada nos conhecimentos prévios dos alunos; questões ligadas à propriedade polissêmica de algumas palavras do português brasileiro. Esses seriam alguns caminhos que o estudioso poderia seguir para analisar a situação na perspectiva da LC.

A questão das inferências que realizamos diante de um discurso é sempre fundamentada no nosso experiencialismo. Muitas vezes, ao não compreendermos uma determinada palavra, tendemos a fazer analogia, ou seja, relacionar o termo com outro que seja do nosso conhecimento linguístico. Daí observamos os mal entendidos em ditos populares, por exemplo: o famoso "cuspido e escarrado" é uma analogia para a expressão "esculpido e encarnado" - a última construção contém palavras que não são tão usuais na nossa língua, então houve a associação com o que é mais usual, decorrendo a prevalência da primeira construção como a correta para exprimir alguém que seja muito semelhante a um familiar.

Vieira (2000, p.2), dentro da abordagem sociocognitiva da semântica textual, afirma que o cognitivismo considera o conhecimento adquirido pelo homem a partir de três domínios: as histórias, os scripts e as cenas. As histórias estão ligadas a esquemas (papéis 
desempenhados pelos conhecimentos na compreensão, memorização e produção de inferências); os scripts representam eventos cotidianos (rotinas e trabalho diário); as cenas representam lugares nos quais as rotinas têm lugar. Essas três estruturas estão representadas em nossa mente por formas esquemáticas de organização; elas são essenciais na realização de inferências pragmáticas.

O problema da não compreensão de um conceito passa também pelo processo de categorização; categorizar é uma ação intrínseca ao ser humano, mas para realizá-la é necessário um parâmetro (protótipo). Quando o aluno é apresentado, por exemplo, ao conceito de nomes substantivos, há propriedades que lhe são apresentadas para que ele consiga identificar essa categoria; o conceito de um gênero textual decorre também da categorização, quando há a apresentação das características do gênero. Por conta das características observadas em um gênero textual como o poema, o aluno vai ter condições de não confundi-lo, por exemplo, com o conto. Se o professor não tiver consciência dos processos de categorização que ocorrem enquanto trabalha um determinado conteúdo, a tendência de não acontecer a aprendizagem é muito grande.

\section{d) Que objetos de pesquisa podem ser considerados para uma análise eficaz}

\section{pela LC?}

Ao se falar sobre objetos de pesquisa, primeiramente devemos considerar que muitos objetos de estudo emergem de situações reais, não programadas. Então, falaremos acerca de alguns objetos que poderão ser analisados pela LC, mas na certeza de que essa exposição não é exaustiva.

Considerando que o ambiente de análise é a sala de aula, podemos pensar em todas as situações relacionadas a esse ambiente e perpassadas pelo linguístico: a explanação de uma aula, a apresentação de trabalhos, a interação dos alunos durante a correção de um exercício, respostas dadas por escrito em uma determinada atividade (voltadas para a interpretação de textos ou para a análise linguística), sequências didáticas de um determinado gênero textual, orientações ou protocolos de atividades orais ou escritas; enfim, há uma 
gama de atividades realizadas em sala de aula que podem se tornar objetos analisáveis pelos pressupostos da LC.

Também evidenciamos a análise de textos produzidos pelos alunos a partir de uma proposta baseada em um gênero textual específico. A observação de manutenção da proposta, bem como o encadeamento das construções frasais são objetos de estudos valiosos para fenômenos linguísticos e detecção de aprendizagem das habilidades de escrita do aluno.

A produção de materiais didáticos alinhados aos pressupostos da LC também servem como objetos de pesquisa, uma vez que sua elaboração decorre do conhecimento de aspectos das linguagens no âmbito cognitivista, tomando como ponto de partida a proposta interativa do material criado e a abordagem em um dos aspectos relacionados (perspectiva, categorização, MCI, projeção de espaços mentais, etc).

\section{e) Esse tipo de análise é realmente produtivo?}

Cremos que, diante do exposto até aqui, haja elementos suficientes para demonstrar a produtividade da análise da LC nas situações de sala de aula. Apesar disso, enfatizamos os aspectos produtivos desse tipo de análise:

- Interface com outras áreas de estudo, gerando uma análise mais aprofundada e abrangente sobre o objeto de pesquisa.

- Possibilidade de trabalhar os multiletramentos de forma autêntica, uma vez que a análise será das linguagens e não somente de uma linguagem.

- Inovação nas propostas de materiais didáticos, que atenderão à demanda de aprendizagem do aluno e servirão como referência para a criação de outras sequências didáticas.

Esses são alguns dos pontos vantajosos da análise pela LC. À medida que as atividades forem realizadas, certamente surgirão mais elementos produtivos. 


\section{Prática pedagógica e Linguística Cognitiva: como fazer?}

Este tópico, em primeira análise, poderia estar vinculado às perguntas realizadas no tópico anterior, mas, no objetivo de enfatizar a questão, preferimos fazê-lo à parte. É recorrente a ideia de que todas as vezes em que há uma proposição de prática pedagógica de uma abordagem teórica "nova” haja também a preparação (qualificação) para essa prática. Como preparação, compreendemos a articulação entre o discurso teórico da LC, a análise das situações em sala de aula e a capacitação de docentes para a execução das atividades.

No pensamento de que somente através dessa articulação poderemos iniciar um trabalho efetivo na sala de aula, sugerimos que ocorram oficinas de materiais didáticos que forneçam aos docentes o necessário para que possam aplicar atividades dentro dos objetivos da LC. Também seria interessante haver encontros entre professores para compartilhamento de ideias, grupos de estudo e suporte pedagógico de especialistas para a observação das práticas aplicadas.

As práticas pedagógicas devem ser enxergadas, então, no âmbito da mediação realizada pelo professor com os alunos em sala de aula e compartilhada com seus pares (outros professores e especialistas) em um ambiente de formação continuada. Esse professor é aquele que terá a postura investigativa diante dos avanços e conflitos gerados por essas práticas. Não se concebe outra perspectiva quando nos referimos a um ensino reflexivo.

Não existe uma "receita" para se fazer a aplicação da LC em sala de aula, mas pensamos que uma formação continuada voltada especificamente para essa abordagem teórica seria o mais adequado nesse processo.

\section{Considerações finais}

Para sintetizar as ideias apresentadas neste artigo, pensando nos futuros trabalhos decorrentes desta empreitada, consideramos o seguinte: 
a)A sala de aula tem sido um espaço de ampla análise por várias vertentes teóricas da atualidade, todas no intuito de contribuírem para um aprofundamento nas práticas pedagógicas já executadas e uma melhoria no desempenho de tantas outras práticas a serem descobertas.

b) $\mathrm{O}$ advento tecnológico nos impõe uma abordagem focada nas linguagens, o que colabora para o surgimento de novos métodos de análise, que deem conta de registrarem os cenários decorrentes dessa atual conjuntura e a aplicabilidade de ferramentas eficazes nos processos de ensino e aprendizagem. c) Os estudos sobre a cognição têm sido realizados no viés da Psicologia da Aprendizagem, mas muito ainda precisa ser estudado no que diz respeito aos processamentos cognitivos que ocorrem durante a realização de uma aula, processos ad hoc, que precisam ser considerados em uma proposta pedagógica que vise ao desenvolvimento de habilidades de leitura, escrita, fala e escuta.

d)Ignorar as contribuições da Linguística Cognitiva para o ensino é desconsiderar os processos de ensino e aprendizagem como multifacetados e passíveis de transformação de acordo com a didática utilizada.

\title{
COGNITIVE LINGUISTICS IN THE CLASSROOM: POSSIBLE FORWARDINGS
}

\begin{abstract}
The article aims to present the assumptions of Cognitive Linguistics as viable tools for the analysis of pedagogical practices in the classroom. Based on the initiatives of Alves (2005) and Gerhardt (2006), we argue that the analysis through cognitive concepts such as frame, joint attention scene, construal, ICM (idealized cognitive model), mental spaces and categorization is a contribution to improvement of teaching practices and of the understanding of the teaching and learning processes in the different disciplines pervaded by languages. In this bias, we also present some perspectives for the study of Cognitive Linguistics as a basis for analysis of pedagogical practices and also for the production of protocols and didactic materials aimed at the development of reading, writing, speaking and listening.
\end{abstract}

KEYWORDS: Cognitive Linguistics. Teaching. Pedagogical practice. 


\section{REFERÊNCIAS}

ALVES, M.F. Interação e cognição em sala de aula. Tese de doutorado - Universidade Federal de Pernambuco. CAC. Linguística, 2005.

BARBOSA, A.F. O papel da linguística cognitiva na formação do professor de alemão como língua estrangeira: um estudo sobre o ensino da preposição alemã über com base em esquemas imagéticos e metáforas conceptuais. Dissertação de mestrado - Universidade Federal de Minas Gerais. Pós-Graduação em Estudos Linguísticos, 2015.

BORTONI-RICARDO, S.M. Educação em lingua materna: a sociolinguística em sala de aula. São Paulo: Parábola, 2004.

CHIAVEGATTO, V.C. Introdução à Linguística Cognitiva. Matraga, Rio de Janeiro, v.16, n.24, jan./jun. 2009.

CROFT, W \& CRUSE, A. Cognitive Linguistics. Cambridge: Cambridge University Press, 2004.

FERRARI, LILIAN. Introdução à linguística cognitiva. São Paulo: contexto, 2011.

FILLMORE, C.J. Frame semantics. In: Linguistics in the Morning Calm, Seoul, Hanshin Publishing Co., 1982, p. 111-137.

GERHARDT, A. F.L.M. Uma visão sociocognitiva da avaliação em textos escolares. Educ. Soc., Campinas, vol. 27, n. 97, p. 1181-1203, set./dez. 2006.

LAKOFF, G. Women, fire, and dangerous things: what categories reveal about the mind. Chicago: The University of Chicago Press, 1987.

; JOHNSON, M. Metáforas da vida cotidiana. Coordenação de tradução: Mara Sophia Zanotto. São Paulo: Mercado das Letras, 2002 [1980].

MARCUSCHI, L.A. O diálogo no contexto da aula expositiva: continuidade, ruptura e integração. Recife (mimeo), 2004, p. 1-20.

MEC.BRASIL. Base Nacional Comum Curricular. 2017. Disponível em $<$ basenacionalcomum.mec.gov.br/a-base>. Acesso em 21/02/2018

. Parâmetros curriculares nacionais: língua portuguesa (1ª a $4^{a}$ séries). Brasília, 1997.

PORTAL, F.B. Explorando o potencial da linguística cognitiva para o ensino-aprendizagem da preposição in em aulas de inglês como língua estrangeira. Dissertação de mestradoUnisinos. PPG Linguística Aplicada, 2014.

SILVA, A.S. A linguística cognitiva - Uma breve introdução a um novo paradigma em linguística. Revista portuguesa de bumanidades, ISSN 0874-0321, Vol. 1, No 1-2, 1997, págs. 59101.

SOARES, M. Alfabetização e letramento. 7.ed. São Paulo: Contexto, 2017. 
TOMASELLO, M. Origens culturais da aquisição do conbecimento bumano. São Paulo: Martins Fontes, 2003.

TRIPP, D. Pesquisa-ação: uma introdução metodológica. Educação e Pesquisa, São Paulo, v. 31, n. 3, p. 443-466, set./dez. 2005.

VIEIRA, N.S.J.S. Do corpus à cognição: aspectos cognitivos de semântica textual. In: Forum media: revista do curso de comunicação social. - Viseu. - (2), Maio, 2000. Disponível em http://www.ipv.pt/forumedia/f2_menu3.htm

Recebido em: 30/04/2019.

Aprovado em: 25/07/2019. 